\title{
PENGARUH GERHANA MATAHARI 09 MARET 2016 TERHADAP KANDUNGAN TOTAL ELEKTRON IONOSFER
}

\author{
Aprilia Nur Vita ${ }^{1, a),}$ Bambang Sunardi ${ }^{1, b)}$,Sulastri ${ }^{1)}$, Andi Eka Sakya ${ }^{1)}$
}

${ }^{1}$ BMKG, Jl. Angkasa I/No.2 Kemayoran, Jakarta 10720

Email: a)aprilia.nurvita@gmail.com, b)bambang.sunardi@bmkg.go.id

\begin{abstract}
Abstrak
Kandungan total elektron di ionosfer dipengaruhi oleh beberapa faktor, diantaranya waktu lokal, aktifitas matahari, gangguan geomagnet, lintang dan bujur geografis. Penelitian ini dilakukan untuk mengetahui perubahan nilai total kandungan elektron di ionosfer selama gerhana matahari total yang melintasi Indonesia 09 Maret 2016. Data yang digunakan adalah GPS-TEC pada dua stasiun di lokasi yang mengalami gerhana matahari dengan magnitudo berbeda. Stasiun yang digunakan adalah Bitung (BTNG) dan Yogyakarta (JOG2). Wilayah Bitung mengalami gerhana matahari dengan magnitudo mencapai 0,97 sedangkan wilayah Yogyakarta mengalami gerhana matahari dengan magnitudo 0,849. Data GPS-TEC pada hari gerhana dibandingkan dengan data satu hari sebelum dan satu hari sesudah gerhana yang diasumsikan sebagai nilai GPS-TEC normal. Hasil penelitian menunjukkan nilai kandungan total elektron mengalami anomali pada hari gerhana. Stasiun BTNG merekam anomali nilai kandungan total elektron yang lebih signifikan dibandingkan anomali yang terekam di stasiun JOG2.
\end{abstract}

Kata Kunci: Kandungan total elektron,ionosfer, gerhana matahari, GPS, Jogjakarta, Bitung.

\begin{abstract}
Total electron content in the ionosphere is affected by several factors, local time, solar activity, geomagnetic disturbance, geographical latitude and longitude. This research aims to observe level variation of total electron content during solar eclipse over Indonesia on 09 March 2016. We analyzed GPS data from two GPS stations in different locations with different suns obscuration magnitude, which are Bitung Station (BTNG) and Yogyakarta station (JOG2). The magnitude of solar eclipse in Bitung Area was 0.97, while the solar eclipse magnitude in Yogyakarta reached 0.849. In addition, the data are obtained a day before, during, and a day after the solar eclipse, then compared to investigate the anomaly. Data from the previous day and a day after the solar eclipse assumed as normal data. From the result, it shows that more significant TEC anomaly recorded in Bitung if comparing with TEC variation in Yogyakarta.
\end{abstract}

Keywords: Total Electron Content, ionosphere, solar eclipses, GPS, Yogyakarta, Bitung 


\section{PENDAHULUAN}

Gerhana matahari merupakan fenomena alam yang terjadi ketika cahaya matahari yang menuju bumi terhalang bulan baik sebagian maupun seluruhnya. Gerhana matahari hanya berlangsung saat bulan berada pada fase bulan baru dan dapat diperkirakan waktu kejadiannya. Walaupun bulan fase bulan baru terjadi setiap 29 1/2 hari, namun kejadian gerhana matahari tidak terjadi setiap bulan. Gerhana matahari hanya terjadi jika posisi matahari, bulan dan bumi sejajar secara geometris sehingga terbentuk bayangan bulan di bumi. Pada tahun 2016 diperkirakan terjadi 5 kali gerhana, salah satunya adalah gerhana matahari total 09 Maret 2016 yang dapat diamati dari Indonesia [1]

Berdasarkan BMKG, gerhana matahari total 09 Maret 2016 dapat terlihat di sejumlah wilayah di benua Asia, Australia dan Amerika. Jalur totalitas GMT 09 Maret meliputi wilayah Indonesia dan Samudra Pasifik. Namun hanya 45 kota dan kabupaten di 12 propinsi yang dapat menyaksikan gerhana matahari total, sedangkan wilayah yang lain mengalami gerhana matahari sebagian (Gambar 2) Kota yang mengalami waktu mulai gerhana paling awal adalah Kotaagung, Lampung pada pukul 06:19:41,0 sedangkan waktu mulai gerhana paling akhir adalah Waris, Papua pada pukul 08:53:44,1 WIT. Totalitas terlama pada GMT 09 Maret terjadi di Maba, maluku Utara selama 3 menit dengan magnitudo 1,019, sementara durasi gerhana terlama di Indonesia adalah di jayapura selama 2 jam 55 menit 3,0 detik.

Gerhana matahari akan mempengaruhi kandungan elektron di ionosfer akibat berkurangnya radiasi matahari ke ionosfer. Kandungan elektron di ionosfer dipengaruhi oleh beberapa faktor antara lain lintang dan bujur geografis, waktu lokal, aktivitas matahari, dan gangguan geomagnet [2] pengaruh gerhana matahari terhadap ionosfer dapat berlangsung selama beberapa jam setelah totalitas terbesar [3] Saat ini data GPS telah banyak dimanfaatkan untuk penelitian mengenai gangguan ionosfer ysng diakibatkan oleh alam maupun buatan , seperti gempabumi [4]. Penelitian ini dilakukan untuk mengetahui efek gerhana matahari terhadap ionosfer berdasarkan data Total Electron Content (TEC)/kandungan total elektron yang diperoleh dari data GPS. Data yang dipergunakan adalah data satu hari sebelum, saat dan sesudah kejadian. Data diambil dari dua stasiun yang terletak di lokasi yang mengalami gerhana matahari dengan magnitudo berbeda, yaitu stasiun Bitung (BTNG) dan Jogjakarta (JOG2). Bitung mengalami gerhana dengan magnitudo 0.97, sedangkan magnitudo gerhana di Jogjakarta 0,85 [1] , perbedaan magnitudo gerhana 0,9 dan 0,8 dapat dilihat di Gambar 1.

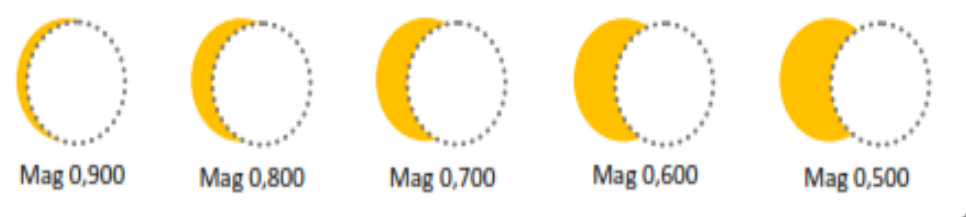

GAMBAR 1 Ilustrasi perbandingan magnitudo gerhana matahari [1]

Penelitian mengenai pengaruh gerhana matahari terhadap ionosfer di Eropa memperlihatkan penurunan nilai TEC bergantung pada magnitudo gerhana [3]. Penurunan nilai TEC akibat gerhana matahari berkisar $20-30 \%$, dan terdapat jeda waktu beberapa menit dari puncak gerhana ke penurunan nilai TEC terbesar [5].

\section{METODE PENELITIAN}

Peta lintasan gerhana matahari dan lokasi stasiun yang digunakan pada penelitian ini ditunjukkan oleh gambar 3 dan gambar 4. Data GPS yang digunakan meliputi data dari stasiun BTNG dan JOG2 satu hari sebelum, saat, dan sesudah kejadian gerhana. Seluruh data GPS diunduh dari website SOPAC data center yang menyediakan data dari International GNSS services (IGS) station. Unduhan data dalam format RINEX kemudian diubah menjadi data TEC dengan menggunakan Rinex GPSTEC program V2.9. Hasil berupa nilai TEC kemudian di plot dalam grafik seri waktu. Analisa 
kecenderungan perubahan nilai TEC satu hari sebelum, saat dan sesudah gerhana matahari pada jam puncak gerhana dilakukan untuk melihat efek gerhana di ionosfer.

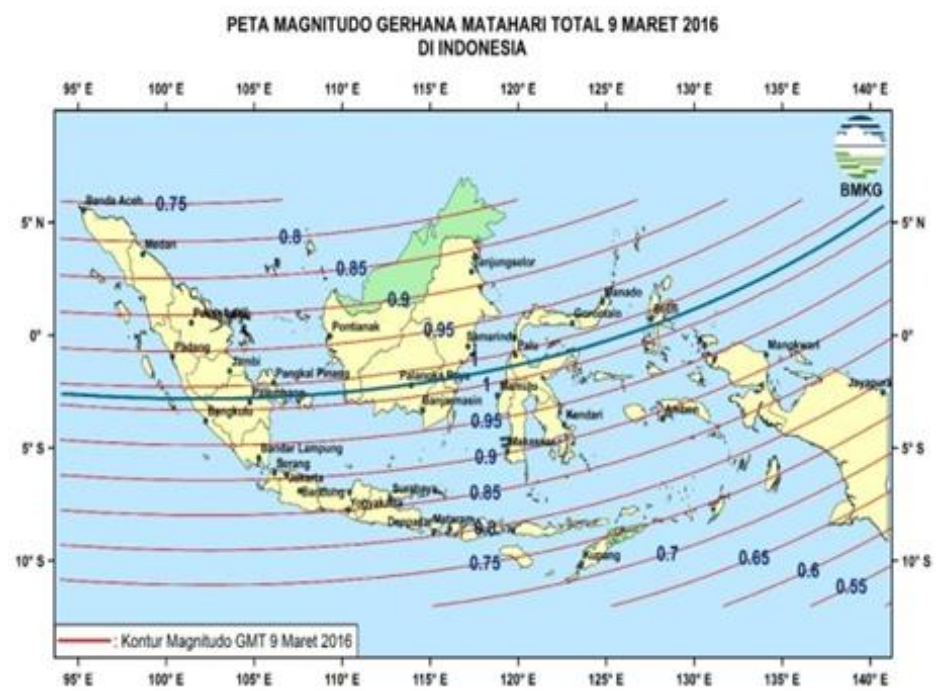

GAMBAR 2. Peta Lintasan dan Magnitudo Gerhana Matahari Total 09 Maret 2016 di Indonesia [1]

Penurunan nilai TEC pada saat gerhana matahari dapat diakibatkan oleh beberapa factor antara lain nilai awal, lokasi, sudut datang sinar matahari, perbedaan waktu lokal pada saat puncak gerhana dan magnitudo[3]. Namun pada makalah ini hanya akan menganalisa kemungkinan pengaruh magnitudo terhadap perubahan nilai TEC. Dibutuhkan penelitian yang lebih mendalam untuk mengetahui pengaruh dari faktor-faktor lain.

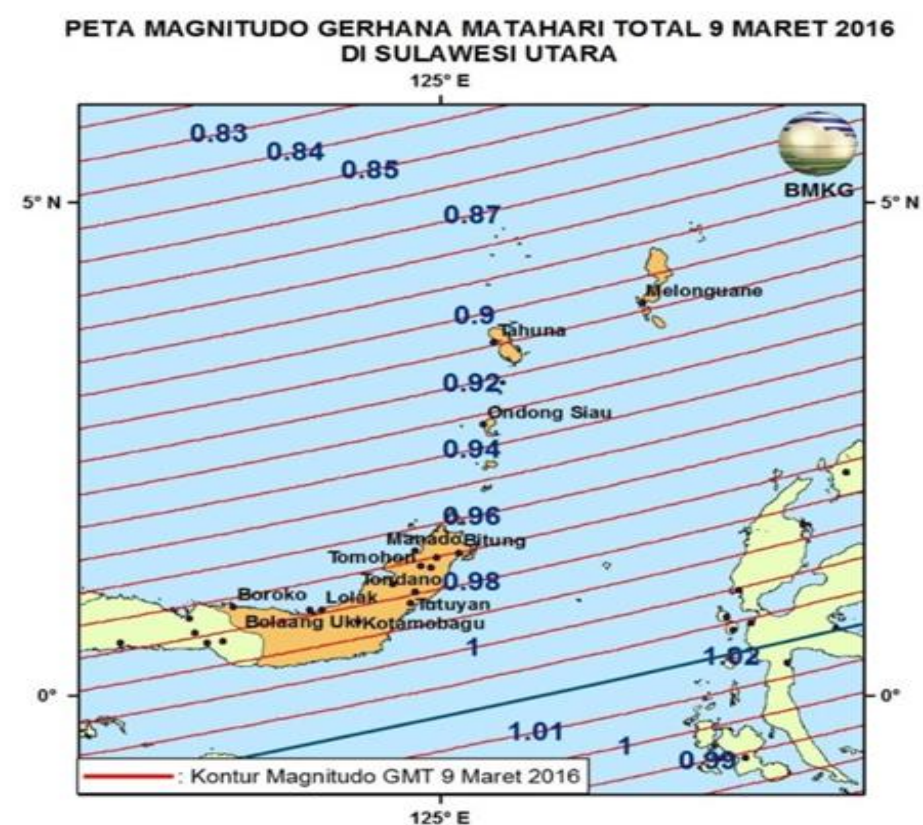

GAMBAR 3. Peta Lintasan dan Magnitudo Gerhana Matahari Total 09 Maret 2016 di Sulawesi Utara [1] 


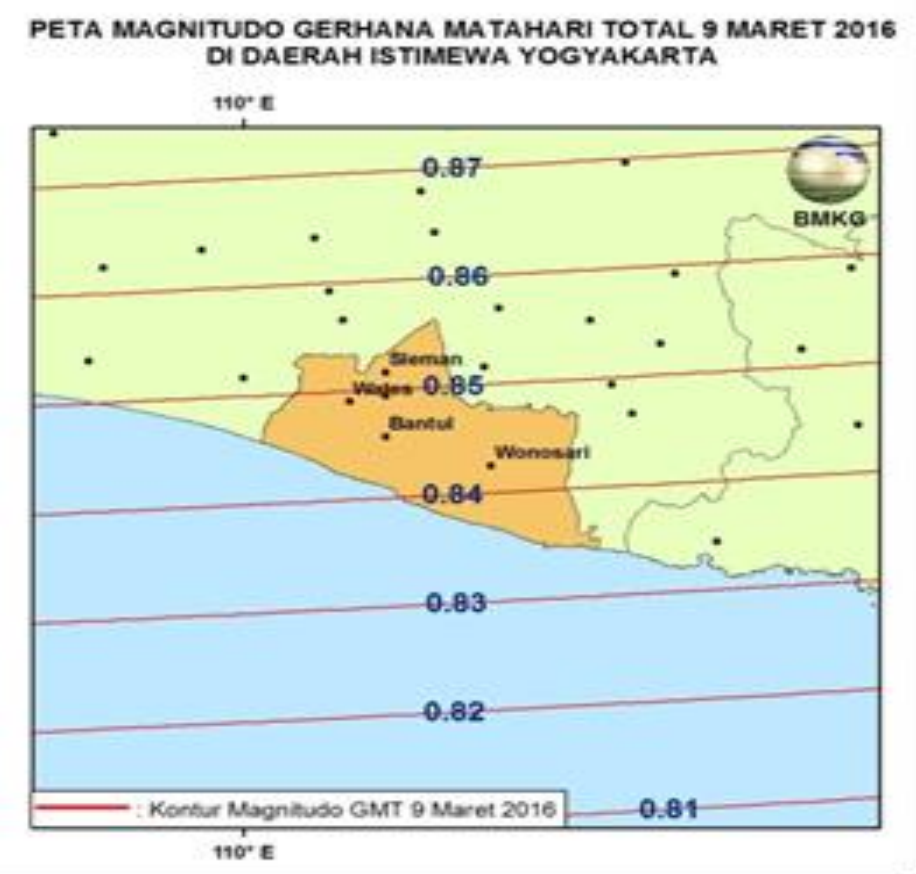

GAMBAR 4. Peta Lintasan dan Magnitudo Gerhana Matahari Total 09 Maret 2016 di DIY [1]

\section{HASIL DAN PEMBAHASAN}

Nilai total kandungan elektron di lokasi terpilih pada saat kejadian gerhana matahari dibandingkan dengan nilai pada satu hari sebelum dan sesudah gerhana matahari. Analisis dilakukan pada pukul 08:00 sampai dengan 12:00 WITA (UTC+8).

Gambar 5 memperlihatkan kecenderungan perubahan nilai total elektron pada 08, 09, dan 10 April 2016. Di wilayah Bitung, gerhana matahari dimulai pada pukul 7:34:21.5 WITA,mengalami puncak pada 08:49:38.4 WITA dan berakhir pada pukul 10:15:56.5 WITA [1]

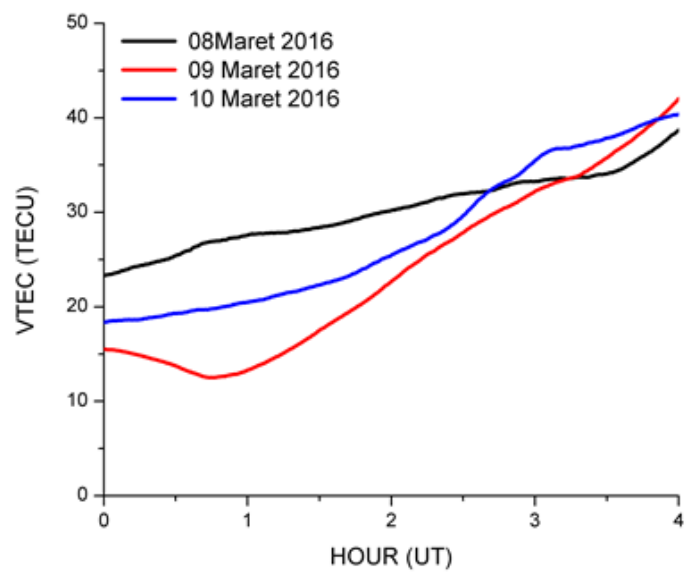

GAMBAR 5. Perubahan Nilai TEC di Stasiun BTNG

Pada Gambar 5 terlihat nilai VTEC pada tanggal 08 dan 10 Maret 2016 dari pukul 00:00 sampai 04:00 UTC meningkat seiring waktu, sedangkan pada 09 Maret 2016 nilai TEC mengalami penurunan dari pukul 00:00 sampai 01:00 UT kemudian mengalami peningkatan . Pada pukul 00:00 UTC gerhana matahari di Bitung sedang berlangsung dan mendekati fase puncak. 
Data nilai TEC stasiun BTNG tiap 10 menit pukul 00:00 sampai 01:00 UT ditampilkan pada Tabel 1. Dari tabel tersebut terlihat nilai kandungan elektron tanggal 09 Maret pukul 00:00 sampai 01:00 menurun dari 15,53 ke 13,31 dan mencapai nilai minimum pada pukul 00:50 sebesar 12,66.

TABEL 1. Perubahan Nilai TEC Stasiun BTNG

\begin{tabular}{llll}
\hline \multirow{2}{*}{ Time (UT) } & \multicolumn{2}{c}{ TECU } \\
\cline { 2 - 4 } & 08 Mar & $09 \mathrm{Mar}$ & $10 \mathrm{Mar}$ \\
\hline $00: 00$ & 23,32 & 15,53 & 18,34 \\
$00: 10$ & 23,96 & 15,17 & 18,64 \\
$00: 20$ & 24,65 & 14,52 & 18,86 \\
$00: 30$ & 25,43 & 13,73 & 19,3 \\
$00: 40$ & 26,55 & 12,77 & 19,71 \\
$00: 50$ & 27,1 & 12,66 & 20,01 \\
$01: 00$ & 27,59 & 13,31 & 20,52 \\
\hline
\end{tabular}

Gambar 6 menunjukkan grafik perubahan kandungan elektron pada 08, 09 dan 10 Maret 2016 pukul 00:00 hingga 04:00 UTC di Yogyakarta. Kontak pertama gerhana matahari di Jogjakarta terjadi pada pukul 06:20:32.1 WIB (UT+7), puncak gerhana terjadi pada pukul 07:23:30.6 dan gerhana berakhir pada pukul 08:35:16,1.

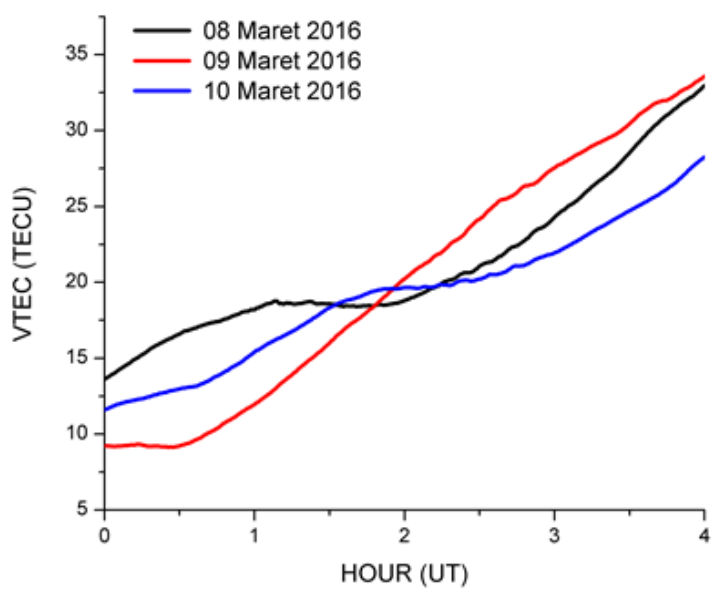

Grafik perubahan kandungan elektron tanggal 09 Maret 2016 pada Gambar 6 tidak memperlihatkan adanya penurunan yang signifikan saat gerhana matahari mendekati puncak sebagaimana yang terlihat di Gambar 5 .

Pada tabel 2 terlihat Nilai TEC 09 Maret 2016 mengalami perubahan yang sangat kecil pada pukul 00:00 hingga 00:30 yaitu 9,22 ke 9,21. Berbeda dengan perubahan nilai TEC pada 09 dan 10 Maret, yang berubah 3,01 dan 1,9 TECU dalam waktu 30 menit.

Dari Gambar 5 dan 6 terlihat perubahan nilai TEC yang lebih signifikan di wilayah Bitung yang mengalami gerhana matahari dengan magnitudo 0,97, dibandingkan dengan wilayah Yogyakarta yang mengalami gerhana matahari dengan magnitudo 0.87 .

Hal ini disebabkan oleh tingkat ionosasi di ionosfer oleh matahari lebih rendah di wilayah Bitung dibadinngkan di wilayah Yogyakarta akibat lebih besarnya bagian matahari yang terhalang oleh bulan. 
TABEL 2. Perubahan Nilai TEC Stasiun JOG2

\begin{tabular}{llll}
\hline \multirow{2}{*}{ Time $(\mathrm{UT})$} & \multicolumn{2}{c}{ TECU } \\
\cline { 2 - 4 } & 08 Mar & 09 Mar & 10Mar \\
\hline $00: 00$ & 13,6 & 9,22 & 11,59 \\
$00: 10$ & 14,67 & 9,27 & 12,17 \\
$00: 20$ & 15,79 & 9,21 & 12,59 \\
$00: 30$ & 16,61 & 9,21 & 12,98 \\
$00: 40$ & 17,21 & 9,93 & 13,39 \\
$00: 50$ & 17,69 & 10,92 & 14,31 \\
$01: 00$ & 18,18 & 11,97 & 15,4 \\
\hline
\end{tabular}

Jeda waktu antara mulai gerhana dengan waktu pengaruh gerhana di ionosfer tidak dapat diketahui karena pada pukul 00:00 UT, gerhana matahari di kedua wilayah sudah dimulai. Sedangkan jeda waktu antara puncak gerhana dengan waktu nilai $T E C$ tercatat paling kecil saat gerhana adalah 1 menit di Bitung dan 7 menit di Yogyakarta.

\section{SIMPULAN}

Penelitian ini meneliti mengenai respon ionosfer terhadap gerhana matahari pada 09 Maret 2016 di Bitung dan Yogyakarta menggunakan data GPS. Perubahan nilai TEC pada saat kejadian gerhana dibandingkan dengan satu hari sebelum dan sesudah kejadian. Analisa dimulai dari pukul 00:00 sampai 04:00 UT. Dari pengamatan terlihat nilai TEC menurun pada saat kejadian gerhana matahari. Perubahan yang lebih signifikan terjadi di wilayah yang mengalami gerhana dengan magnitudo lebih besar.

\section{UCAPAN TERIMAKASIH}

Penulis mengucapkan terimakasih kepada BMKG yang telah memberikan dukungan dan telah memberikan data waktu gerhana, SOPAC Data Center yang menyediakan unduhan data GPS, dan Dr.Gopi Seemala untuk program RINEX GPS-TEC v2.9

\section{DAFTAR ACUAN}

[1] BMKG, "GERHANA MATAHARI TOTAL 09 MARET 2016”, BMKG., Jakarta, Maret, 2016

[2] Norsuzila Ya'acob, Wan Muhammad Faizhaqimi Wan Hasbullah, Nor Farhana Azmi, Azita Laily Yusof, Mohamad Huzaimy Jusoh, "GPS Ionospheric Scintillation and Total Electron Content during partial solar eclipse in Malaysia", Signal Processing \& its Applications (CSPA) 2014 IEEE 10th International Colloquium on, pp. 276-281, 2014

[3] Hoque MM, Wenzel D, Jakowski N, Gerzen T, Berdermann J, et al. "Ionospheric response over Europe during the solar eclipse of March 20, 2015". J. Space Weather Space Clim., 6, A36, 2016, DOI: $10.1051 / \mathrm{swsc} / 2016032$.

[4] Calais, Eric, and J. Bernard Minster. "GPS detection of ionospheric perturbations following the January 17, 1994, Northridge earthquake." Geophysical Research Letters 22.9 (1995): 1045-1048.

[5] Cohen, Elizabeth A. "The study of the effect of solar eclipses on the ionosphere based on satellite beacon observations." Radio Science19.03 (1984): 769-777. 